\title{
Human Networks and Toxic Relationships
}

\author{
Nazaria Solferino ${ }^{1}$ and Maria Elisabetta Tessitore ${ }^{2, *}$ \\ 1 Economics Department, University of Calabria UNICA, Via Ponte Pietro Bucci 1C, Arcavacata di Rende, \\ 86133 Cosenza, Italy; nazaria.solferino@unical.it \\ 2 Economics Department, University of Rome Tor Vergata, Via Columbia 2, 00133 Rome, Italy \\ * Correspondence: tessitore@economia.uniroma2.it
}

\begin{abstract}
We devise a theoretical model to shed light on the dynamics leading to toxic relationships. We investigate what intervention policy people could advocate to protect themselves and to reduce suffocating addiction in order to escape from physical or psychological abuses either inside family or at work. Assuming that the toxic partner's behavior is exogenous and that the main source of addiction is income or wealth we find that an asymptotically stable equilibrium with positive love is always possible. The existence of a third unconditionally reciprocating part as a benchmark, i.e., presence of another partner, support from family, friends, private organizations in helping victims, plays an important role in reducing the toxic partner's appeal. Analyzing our model, we outline the conditions for the best policy to heal from a toxic relationship.
\end{abstract}

Keywords: dynamical systems; stability; economics; relationships; networks

JEL Classification: C62; D11; D91

\section{check for}

updates

Citation: Solferino, N.; Tessitore, M.E. Human Networks and Toxic Relationships. Mathematics 2021, 9, 2258. https://doi.org/10.3390/ math9182258

Academic Editor: David Carfi

Received: 27 July 2021

Accepted: 9 September 2021

Published: 14 September 2021

Publisher's Note: MDPI stays neutral with regard to jurisdictional claims in published maps and institutional affiliations.

Copyright: (c) 2021 by the authors. Licensee MDPI, Basel, Switzerland. This article is an open access article distributed under the terms and conditions of the Creative Commons Attribution (CC BY) license (https:// creativecommons.org/licenses/by/ $4.0 /)$.

\section{Introduction}

In this paper, we aim to give an additional contribution to the literature in Economics of Love devising a modified version of the model in [1]. We analyse the dynamics leading to toxic relationships, i.e., we focus our attention on situations where love is transformed into a negative dependence and the relationship produces a dangerous addiction.

Moreover, we investigate what intervention policy people could advocate to protect themselves and to reduce suffocating addiction in order to escape the trap of physical or psychological abuse either in family or at work. The dynamics of couples' relationships are analyzed through a system of differential equations representing the laws of motions of the amount of love that two individuals put in a relationship which also depends on any source of partner's appeal (financial, physical, intellectual, co-parenthood, etc.).

In our work, the appeal is assumed to change over time proportionally to both the effect of the other partner's love and to a variable representing the main source of addiction (for instance, wealth, status, physical appearence, etc.). The aim of our analysis is to build a model which takes into account the case where toxic relationships are at work, i.e., when one partner chooses to stay in a relationship despite the low or null amount of love received, for the sole reason that their partner's appeal makes it harder for them to terminate the relationship.

In 1995, Dr. Lillian Glass defines a toxic relationship as any relationship [between people who] do not support each other, where there's conflict and one seeks to undermine the other, where there's competition, where there's disrespect and a lack of cohesiveness [2].

By toxic relationship, we mean a relationship disorder characterized by a disparity, a non-egalitarian situation in which one of the two partners is dependent on the other one, triggering a mechanism of dominance and subjection. In these relationships one partner puts into the relationship much more effort than the other one, who, sometimes, could even put no effort at all into it. In an healthy relationship partners can still cut out their 
spaces, maintaining a capacity for self-determination and taking benefit from reciprocity. In a toxic relationship the emotional dependance enters into play, making the partner our exclusive interlocutor, so that being happy and enthusiastic depends exclusively on the other person, just like drug addiction. In order to avoid the abandonment and the consequent lack of affection, the addicted partner cancels himself or herself out, while the counterpart exploits the relationship to feel admired and to exercise control. A toxic relationship implies psychological, and at times physical, violence, and can develop into a tragic eposide of murder. The majority of the victims of these murders are women

Another typical example of toxic relationship is bullying at a workplace, very often put into action by the boss. The unwillingness to call out such behaviour by the victims and spectators results in to favoring it. The reason for this behaviour is obviously the fear of being involved, of retaliation of some kind or even of losing the job.

In our work, we focus on the conditions which make a toxic relationshio to arise. Due to the exploited parter's addiction, the abusing parter's behaviour seems appealing regardless low affection. In Section 2 we rewiev the literature on this topic. In Section 3 we give an analytical definition of a toxic relationship and we solve an intertemporal dynamic model, where the toxic partner's behaviour is assumed to be exogenous. Assuming that the main source of addiction is income or wealth, we find that an asymptotically stable equilibrium with positive love is always possibile for a high enough level of appeal if subsidies that reduce addiction are introduced. In Section 4, we compare two alternative policies that can be adopted to heal from addiction. One policy consits in healing through a subsidy that can reduce the toxic partner's appeal. The alternative policy is to heal through a third, unconditionally reciprocating, part as a benchmark which represents an alternative, but less attractive, to the partner's love. This third part plays an important role in reducing the toxic partner's appeal. It substantially mimics not only the real presence of another partner but also the support from family, friends and overall private organizations in helping victims of domestic abuses recover their life fully. It may also represent private organizations that offer economic and psychological support as well as legal counselling to victims of bullying at workplace and placement offices which effectively help to find another job. Section 5 contains our discussion and future implications and research.

\section{Literature Rewiev}

A very particular branch of economics literature, only recently developed, is the Economics of Love. It is focused on the household's well-being, marriage and long-term relationships alongside their effects on economic growth (for an exhaustive survey on this literature see $[3,4])$.

The first work in this new field of Economics appeared in the early 1970s with the theory of marriage by Becker [5]. According to it, all individuals want to find a partner with whom they will maximise their own well-being. The equilibrium in this marriage market is reached when no one can change partner or become single and when nobody can experience a higher well-being (referred to the consumption of household commodities).

Beckerś empirical analysis shows that the gain from marriage is positively dependant on income, on relative difference in wage rates and on the level of intangible variables such as education and beauty. Moreover, individuals choose partners with similar traits such as height, race, social background, etc. Including among the factors which can affect marriages also love (defined as a situation where the utility of one individual depends on the commodity consumption of their partner as well as their own), Becker [6] finds that love raises the likelihood of two people to marry because their well-being is likely to be higher.

After these pioneering works, many other analyses have been focused on understanding how households operate. Outcomes of interest concern consumption, savings, labor supply and other uses of time, household formation and dissolution, demand for health and other forms of human capital, fertility and children outcomes, demand for environmental quality, migration, and household produced goods $([3,4])$. 
Many papers also investigated the determinants of long-lasting relationships and their effects on economic development. Among them, Brines and Joyner [7] conducted an empirical study on the stability of marriage and cohabiting couples in the United States. They found that inequality in employment and income among the cohabiting couple increased the chances of separation, although the effect was not symmetric since inequality had a larger impact when the female partner earned more than the male partner. Grossbard [4] studied family as a complex decision unit where partners with potentially different objectives made decisions about consumption, work and fertility. He noticed that couples marry and divorce depending upon their ability to coordinate these activities.

More recently Johnson et al. [8] applied a unique longitudinal approach to study the long-term outcomes of relationships among 3405 couples. This paper was concerned on predictors of relationship longevity, from measures of conflict frequency, types of behaviours experienced during times of conflict, satisfaction with the relationship and whether partners believed their relationships would last or not. The German study's findings showed that complacency is perhaps the most significant trap to avoid: a relationship where partners tried not to fall into that same-old routine can be vital and fulfilling for the years to come.

While there are quite a lot of studies on marriage and cohabiting couples see Motz [9] and Houston [10], there are only few papers which study the economic dynamics of romance from a theoretical point of view.

Rinaldi (1998) proposed a mathematical model based on a linear dynamical system where three aspects of love dynamics are taken into account: the forgetting process (oblivion), the pleasure of being loved (return), and the reaction to the appeal of the partner (instinct). The results of the model showed that the equilibrium turns out to be positive if the appeals of the two individuals are positive. Sprott extended those results and discussed various models of love and happiness, like the model of romance between Romeo and Juliet and the one about triangular relationship to analyse how a third part could affect the stability of a relationship, see Sprott J.C. [11].

Wauer et al. [12] studied human romantic relationships via system dynamics methodology where a non-linear modelling was proposed and analysed, showing that there are short-termed and long-termed fluctuations of personal feelings due to, for instance, biological cycles and varying stresses from the daily job. The variability is expected to be more limited for couples of cautious individuals. In Regan [13] individuals behave in order to optimize their net benefit from a given relationship. The desire to maximize their rewards, to minimize their costs and the inequity of the benefits to contributions among the individuals will cause unhappiness in a relationship. It clearly depends on the role of expectations [14] and on the level of effort that is given to the relationship. This commitment then determines whether or not the relationship will be maintained [15]. Ref. [16] added to the initial model of Rinaldi [1] a crossed interactions among partners to analyse the effects and synergies of learning and adapting to live together. According to the results of this model the system is asymptotically stable if the ratio of appeals is greater than the reciprocal of the ratio of mutual intensiveness coefficient.

\section{Basic Model of a Toxic Relationship}

In this section, we devise a modified version of the model described in [1] where the level of love an individual puts in a relationship varies over time, depending both on oblivion, on the partner's love and on the perception one has of the appeal of the partner.

We denote by 1,2 the submitted and the toxic partner respectively.

We assume for simplicity that the partner 2's appeal perceived by partner $1, A_{1}$, decreases at the same rate of love $x_{1}$ (i.e., oblivion's rate is the same), it increases as individual 1 loves more, and it decreases as fast as the difference between the amount of love partner 2 puts into in the relationship, $\overline{x_{2}}$, and the desired amount of love that partner 1 would expect from partner $2, \hat{x}_{2}$. 
We also assume that $A_{1}$ depends on a constant factor $M_{2}$ of appeal i.e., income, personality, physical appearance, etc.

We study the stability of the following system of dynamic equations:

$$
\left\{\begin{array}{l}
\dot{x}_{1}(t)=-\alpha x_{1}(t)+\beta \overline{x_{2}}+\gamma_{1} A_{1}(t) \\
\dot{A_{1}}(t)=-\alpha A_{1}(t)+k\left[x_{1}(t)+\left(\overline{x_{2}}-\hat{x_{2}}\right)\right]+M_{2}
\end{array}\right.
$$

where

(i) $\quad x_{1}(t)$ is the love, which consists of both passion and intimacy individual 1 has for the partner 2 at time $t$.

(ii) $\alpha$ refers to the forgetting coefficient and measures how quickly the state of love will decrease, exponentially, in the absence of the partner.

(iii) $\beta$ refers to the response of each partner to the love they receive from the other partner

(iv) $\overline{x_{2}}$ is the love the partner 2 puts in the relationship. We assume it is an exogenous variable of the system and it remains constant over time, so that $0 \leq \overline{x_{2}}<x_{1}(t)$, $\forall t \geq 0$.

(v) $A_{1}(t)$ is the appeal factor, It is the partner 1's perception of partner 2 at a time $t$. It is a subjective variable and depends on the perception of the partner at time $t$. It represents the measure of the partner's power of attracting or arousing interest. This is affected by partner 2 possessing specific characteristics ( physical, intellectual, financial etc) that partner 1 is especially sensitive to.

(vi) $\gamma_{1}$ refers to the response coefficients of the appeal of the other partner.

(vii) $k$ measures the sensitivity of an individual with respect to the excessive unreciprocated love given to the partner.

(viii) $\hat{x}_{2}$ is the minimum level of desired love by individual 1

(ix) $M_{2}$ measures the source of partner 2's appeal, it represents the measure of wealth, beauty, etc. For simplicity we assume $M_{2}$ to be constant over time.

We assume that parameters $\alpha, \beta, k, \gamma_{1} \in(0,1]$ and $\overline{x_{2}}, \hat{x_{2}} \in[0,1]$

Definition 1. If there exists a minimum level of desired love $\hat{x_{2}}$ for individual 1 with $\overline{x_{2}} \leq \hat{x_{2}}$ and if $x_{1}>0$ then we say that the relationship between 1 and 2 is a toxic relationship.

In a toxic relationship, individual 1 loves partner 2 even if the partner 2 does not reciprocate (neither at the minimum possible level normally requested $\hat{x_{2}}$ ), since the second partner only provides $\overline{x_{2}}$ and $\overline{x_{2}}<\hat{x_{2}}$.This happens because attraction $A_{1}$ of partner 1 towards partner 2 is very high.

We are going to prove that system (1) has a steady state stable equilibrium.

Proposition 1. Assume $\sqrt{k \gamma_{1}}<\alpha<\beta$ and $M_{2} \geq k \hat{x}_{2}$, then state steady $\left(x_{1}^{*}, A_{1}^{*}\right)$

is an asympotically stable equilibrium for system (1).

$$
\begin{gathered}
x_{1}^{*}=\frac{\alpha \beta \overline{x_{2}}+k \gamma_{1}\left(\overline{x_{2}}-\hat{x_{2}}\right)}{\alpha^{2}-k \gamma_{1}}+\frac{\gamma_{1} M_{2}}{\alpha^{2}-k \gamma_{1}} \\
A_{1}^{*}=\frac{\beta k \overline{x_{2}}+\alpha k\left(\overline{x_{2}}-\hat{x_{2}}\right)}{\alpha^{2}-k \gamma_{1}}+\frac{\alpha M_{2}}{\alpha^{2}-k \gamma_{1}}
\end{gathered}
$$

Proof. Let $A$ be the coefficient matrix of the system

$$
A=\left(\begin{array}{cc}
-\alpha & \gamma_{1} \\
k & -\alpha
\end{array}\right) .
$$

since $\operatorname{det} A>0$ and $\operatorname{tr} A<0$ the conclusion follows. 
Remark 1. Notice that in the steady state equilibrium, the love for the partner is always positive and it grows as the depreciation rate decreases with respect to the sensitivity towards the partner's appeal.

If partner 1 has $\hat{x_{2}}=1$ and partner 2 provides $\overline{x_{2}}=0$, the first partner still loves the second one since

$$
x_{1}^{*}=-\frac{k \gamma_{1}}{\alpha^{2}-k \gamma_{1}}+\frac{\gamma_{1} M_{2}}{\alpha^{2}-k \gamma_{1}}
$$

We notice that if the amount of love partner 2 puts in the relationship is equal to the desired love of partner 1, i.e., $\overline{x_{2}}=\hat{x_{2}}$, then

$$
x_{1}^{*}=\frac{\alpha \beta \overline{x_{2}}}{\alpha^{2}-k \gamma_{1}}+\frac{\gamma_{1} M_{2}}{\alpha^{2}-k \gamma_{1}}
$$

and

$$
A_{1}^{*}=\frac{\beta k \overline{x_{2}}}{\alpha^{2}-k \gamma_{1}}+\frac{\alpha M_{2}}{\alpha^{2}-k \gamma_{1}}
$$

This means that the first partner's love is always positive if the second partner's perceived appeal overcomes the negative impact of the unreciprocated love.

In particular, if $\overline{x_{2}}=\hat{x_{2}}=0$, then

$$
x_{1}^{*}=\frac{\gamma_{1} M_{2}}{\alpha^{2}-k \gamma_{1}}
$$

and

$$
A_{1}^{*}=\frac{\alpha M_{2}}{\alpha^{2}-k \gamma_{1}}
$$

So we see that the partner 1 still loves partner 2 only depending upon the factor $M_{2}$ which represents wealth, or other benefits.

If individual 1 starts loving individual 2 at time $t=0$, then 1 will love 2 forever. This is true unless the love desired by $1 \hat{x_{2}}$ attains a specific value

Proposition 2. If partner 1 has an amount of desired love

$$
\hat{x_{2}}=\frac{\left(\alpha \beta+\gamma_{1} k\right) \overline{x_{2}}+\gamma_{1} M_{2}}{k \gamma_{1}}
$$

then partner 1 stops loving partner 2 .

Proof. From the previous Proposition we see that $x_{1}^{*}=0$ with this choice of $\hat{x_{2}}$.

Definition 2. Individual 1 overcomes a toxic relationship, i.e., 1 is healed, if $x_{1}^{*}=0$.

Remark 2. Hence we see that from the above Proposition, individual 1 is healed only if the love they desire equals a specific amount.

In practice, this is hard to achieve because it is not straightforward for a person to select a specific value of love to put in a relationship. This is why in the next Section we investigate if there are other ways to get out of such a relationship.

\section{Healing}

In this section, we look for conditions to help the submitted partner 1 to heal from toxicity, since in the previous Section this condition could be attained only if the submitted partner has a specific value of desired love $\hat{x_{2}}$.

We are going to consider two possible ways: the first one is by reducing the toxic partner's appeal 2 via a subsidy $S>0$, while the second one is going to be the presence of a third partner denoted by 3 . 
We begin introducing a subsidy $S=s M_{2}$. This represents a payment from the government or another organization to the abused partner to cover personal living expenses they might incur when leaving the relationship, such as rent. Here $s$ is the factor of proportionality chosen by the government.

In system (1) we introduce the subsidy $S$ in the dynamic of $A_{1}$

$$
\left\{\begin{array}{l}
\dot{x_{1}}(t)=-\alpha x_{1}(t)+\beta \overline{x_{2}}+\gamma_{1} A_{1}(t) \\
\dot{A_{1}}(t)=-\alpha A_{1}(t)+k\left[x_{1}(t)+\left(\overline{x_{2}}-\hat{x_{2}}\right)\right]+M_{2}(1-s)
\end{array}\right.
$$

Proposition 3. The subsidy $S=s M_{2}$ with

$$
s=\frac{\alpha \beta \overline{x_{2}}+k \gamma_{1}\left(\overline{x_{2}}-\hat{x_{2}}\right)}{\gamma_{1} M_{2}}+1
$$

is healing individual 1.

Proof. It is easy to see that in this case the steady state $x_{1_{s}}^{*}$ of system (2) is

$$
x_{1 s}^{*}=\frac{\alpha \beta \overline{x_{2}}+k \gamma_{1}\left(\overline{x_{2}}-\hat{x}_{2}\right)}{\alpha^{2}-k \gamma_{1}}+\frac{\gamma_{1} M_{2}(1-s)}{\alpha^{2}-k \gamma_{1}}
$$

hence the result follows from the above assumptions.

Remark 3. Notice that

$$
x_{1 s}^{*}=x_{1}^{*}-\frac{\gamma_{1} M_{2}}{\alpha^{2}-k \gamma_{1}} s
$$

so the subsidy reduces the love of partner one towards partner two.

Another way to heal might be the presence of a third person, denoted by 3, we want to see if 1 can heal from the second partner. System (1) becomes

$$
\left\{\begin{array}{l}
\dot{x_{1}}(t)=-\alpha x_{1}(t)+\beta\left(\overline{x_{2}}-x_{3}\right)+\gamma_{1} A_{1}(t) \\
\dot{A_{1}}(t)=-\alpha A_{1}(t)+k\left[x_{1}(t)+\left(\overline{x_{2}}-\hat{x_{2}}\right)-x_{3}\right]+M_{2}-M_{3}
\end{array}\right.
$$

where $x_{3}$ is the amount of love of individual 3 towards individual 1 and $M_{3}$ with $M_{3}<M_{2}$ is the appeal of the third partner.

Proposition 4. If $x_{3}$ is such that

$$
x_{3}=\overline{x_{2}}+\frac{\gamma_{1}\left[\left(M_{2}-M_{3}\right)-k \hat{x}_{2}\right]}{\alpha \beta+k \gamma_{1}}
$$

then 3 is healing individual 1.

Proof. It is enough to see that in this case the steady state $x_{13}^{*}$ of system (3) is

$$
x_{13}^{*}=\frac{\alpha \beta\left(\overline{x_{2}}-x_{3}\right)+k \gamma_{1}\left[\left(\overline{x_{2}}-\hat{x_{2}}\right)-x_{3}\right]}{\alpha^{2}-k \gamma_{1}}+\frac{\gamma_{1}\left(M_{2}-M_{3}\right)}{\alpha^{2}-k \gamma_{1}}
$$

Remark 4. Notice that

$$
x_{13}^{*}=x_{1}^{*}-\frac{\alpha \beta+k \gamma_{1}}{\alpha^{2}-k \gamma_{1}} x_{3}-\frac{\gamma_{1}}{\alpha^{2}-k \gamma_{1}} M_{3} .
$$

Hence, the third partner reduces the love of partner one towards partner two, similarly to the subsidy's role in the previous case. 
If in addition to partner 3 offering a certain fixed amount of love $\bar{x}_{3}$ to partner 1 there is also a subsidy $\bar{S}=\bar{s} M_{2}$, then proceeding as before we are going to consider the system

$$
\left\{\begin{array}{l}
\dot{x_{1}}(t)=-\alpha x_{1}(t)+\beta\left(\overline{x_{2}}-\bar{x}_{3}\right)+\gamma_{1} A_{1}(t) \\
\dot{A_{1}}(t)=-\alpha A_{1}(t)+k\left[x_{1}(t)+\left(\overline{x_{2}}-\hat{x_{2}}\right)-\bar{x}_{3}\right]+M_{2}(1-\bar{s})-M_{3}
\end{array}\right.
$$

Proposition 5. The subsidy $\bar{S}=\bar{s} M_{2}$ with

$$
\bar{s}=\frac{\alpha \beta\left(\overline{x_{2}}-\bar{x}_{3}\right)+k \gamma_{1}\left[\left(\overline{x_{2}}-\hat{x_{2}}\right)-\bar{x}_{3}\right]}{\gamma_{1} M_{2}}+1-\frac{M_{3}}{M_{2}}
$$

is healing individual 1.

Proof.

$$
x_{13 \bar{s}}^{*}=\frac{\alpha \beta\left(\overline{x_{2}}-\bar{x}_{3}\right)+k \gamma_{1}\left[\left(\overline{x_{2}}-\hat{x_{2}}\right)-\bar{x}_{3}\right]}{\alpha^{2}-k \gamma_{1}}+\gamma_{1} \frac{M_{2}(1-\bar{s})-M_{3}}{\alpha^{2}-k \gamma_{1}}
$$

and the result follows.

Remark 5. Notice that in the previous case we found that if individual 1 loves 2 without a correspondence, then the only way to get $x_{1}=0$ is by introducing a subsidy that counterbalances the addiction due to income $M_{2}$.

Instead, when there is also a third partner there is no need to take $s>1$ because the love term $x_{3}$ also acts as a counterweight. This results in a lower minimum subsidy required to heal partner 1 since

$$
\bar{s}=s-\frac{\left(\alpha \beta+k \gamma_{1}\right) \bar{x}_{3}+\gamma_{1} M_{3}}{\gamma_{1} M_{2}}
$$

\section{Discussion}

A toxic relationship can be defined as a relationship characterized by one partner displaying behaviours that are emotionally and often physically damaging the other partner.

A healthy relationship involves mutual caring, respect, compassion and a strong interest in the partner's happiness. In the couple both individuals share control and decision-making. On the contrary, a toxic relationship is characterized by insecurity, selfcenteredness, dominance and control.

When two individuals have a toxic relationship, we usually look at the toxic partner's behaviour. We must also observe the individual who is the recipient of the toxic behaviour. In fact, according to psychologists, the reasons that push adults into remaining in toxic reationships, which will almost inevitably damage them emotionally or physically, need to be thoroughly investigated. We think that this often happens because addiction may play a very important role: the partner's appeal grows over time regardless of the amount of love the they invest in the relationship.

In this paper, we approach these issues from a theoretical point of view with the purpose of devising an analytical model which can highlight the main points of this problem and can shed light on useful policy solutions. To this purpose we use the model of Rinaldi [1], adding the possibility of the toxic partner's appeal evolving dynamically according to a specific law of motion. Our model assumes the law's dependence on oblivion, on the excess of love with respect to the partner and on a constant parameter that measures the values of the source of addiction(for instance income or wealth, etc.) Our model shows that in the most simple case, where the partner's behaviour is given (exogenous) and hopelessly toxic, there is an asympotically stable equilibrium for high values of addiction, with a submitted partner always in love.

Nevertheless, an opportune measure of correction based on subsidies can be introduced. On the other hand, the lack of government help is often one of the main reasons for the low levels of immediately reported domestic abuses. For instance, according to 
GROVIO(Group of Experts on Action against Violence against Women and Domestic Violence and EstremeConseguences) of the European Council, about $80 \%$ of abuse in Italy happens at home, and there are not enough dormitories to host over 5000 women who have left their houses to escape abusive partners. Alongside dedicated laws, penalties and high compensation for the monetary, biological and moral damage, public funds are essential. Furthermore, dedicated public funds play a key role in reducing any dependence on employers or co-workers, and in incentivizing reports from victims. Nevertheless, union organizations offering cheap or free legal help, supporting in searching for other jobs and reintegration are very useful.

To take this problem into account, we look for an alternative policy and we study how the results of our theorethical model change when an alternative third part enters the scene and competes for the submitted parter's love with the toxic partner. In this case lower or zero subsidies can be necessary as the third part works like a substitute to decrease the toxic dependance. Anyway a mix of policy intervention based both on subsidies and on help from third part can be fashioned. Therefore, when a policy based only on subsidies is not sufficient, other factors can be useful to rescue from toxicity.

Often, subsidies are not high enough or people need also to preserve their dignity,security, counselling, etc. In our model for instance a high source of addiction may also come from a very low self esteem which can otherwise be raised offering victims other opportunities like alternative jobs or legal/counseling support. This is why we believe that the best solutions relies in a mix of policies where alonside with the government, private organizations offer support to the victims of abuse as well placement offices in finding new jobs.

With this work we aimed to give a contribution to the literature on Economics of Love and in particular we hope to incentive more theoretical and empirical studies on relationships and to devise better policy solutions. In particular we think that a mix of policies, directly or indirectly created to fight this phenomenon based on monetary help and supportive institutions and organizations could be very effective.

A future development of this paper would be to consider people with low self esteem who are most subject to this kind of addiction and where psychoterapy for couples is strongly needed. In the extreme cases when toxicity externates in physical violence also objective policy solutions are likely to be necessary.

An interesting follow-up investigation we would like pursue is the study of the alltoo-common instances of bullying at the workplace. In these instances, too often abuse and harassment are considered normal events, so that the workers who suffer them prefer to remain silent. This occurs especially when the victim's job position is precarious and when the employer can affect the victim's financial condition on a whim. Istat data for Italy tell us that 9 out of 100 women, during their working life, have suffered harassment or blackmail with a sexual background at work (1 million 403 thousand), but that only $20 \%$ talk about it with someone (usually office colleagues) and only $0.7 \%$ complain, for fear of retaliation, shame, or for a distorted sense of guilt, slander. The company is damaged by these occurrances as well as the workers as the effects are a lower productivity, increased risk of accidents and conflict. The inevitable repercussions then fall on the health service (treatments, drugs) and on the social security system (illnesses, injuries, etc.).

Author Contributions: Both authors equally contributed in every aspect of the writing of this article. Both authors have read and agreed to the published version of the manuscript.

Funding: This research received no external funding.

Institutional Review Board Statement: Not applicable.

Informed Consent Statement: Not applicable.

Data Availability Statement: Not applicable.

Conflicts of Interest: The authors declare no conflict of interest. 


\section{References}

1. $\quad$ Rinaldi, S. Love dynamics. Appl. Math. Comput. 1998, 95, 181-192.

2. Glass, L. Toxic People; Your Total Image Publsihing. 1995. Available online: https://www.drlillianglass.com/wp-content/ uploads/2015/06/Toxic-People_ebook.pdf (accessed on 8 September 2021 ).

3. Browning, M.; Chiappori, P.A.; Weiss, Y. Economics of the Family; Cambridge University Press: Cambridge, UK, 2014.

4. Grossbard, S. The Economics of Marriage; The International Library of Critical Writings in Economics Series; San Diego State University: San Diego, CA, USA, 2015.

5. Becker, G.S. A theory of marriage: Part I. J. Political Econ. 1973, 81, 813-846. [CrossRef]

6. Becker, G.S. A Theory of Marriage in Economics of the Family: Marriage, Children, and Human Capital; University of Chicago Press: Chicago, IL, USA, 1974; pp. 299-351.

7. Brines, J.; Joyner, K. The ties that bind: principles of cohesion in cohabitation and marriage. Am. Sociol. Rev. 1999, 64, 333-355. [CrossRef]

8. Johnson, M.D.; Horne, R.M.; Hardy, N.R.; Anderson, J.R. Temporality of couple conflict and relationship perceptions. J. Fam. Psychol. 2018, 32, 445-455. [CrossRef] [PubMed]

9. Motz, A. Toxic Couples: The Psychology of Domestic Violence; Routledge: Oxfordshire, UK, 2014.

10. Houston, M.J. The Psychology of Abusive/Predatory Relationships; iUniverse: Bloomington, Indiana, 2012.

11. Sprott, C. Dynamics of Love and Happiness; Stenberg, R.J., Barnas, M.L., Eds.; Chaos and Complex Systems Seminar in Madison: Madison, WI, USA, 2001.

12. Wauer, J.; Schwarzer, D.; Cai, G.Q.; Lin, Y.K. Dynamical models of love with time-varying fluctuations. Appl. Math. Comput. 2007, 188, 1535-1448. [CrossRef]

13. Regan, P.C. The Mating Game: A Primer on Love, Sex, and Marriage; Sage Publications: London , UK, 2008.

14. Thibaut, J.W.; Kelley, H.H. The Social Psychology of Groups; Routledge: London, UK, 2007.

15. Rusbult, C.E. A longitudinal test of the investment model: The development (and deterioration) of satisfaction and commitment in heterosexual involvements. J. Personal. Soc. Psychol. 1983, 45, 101-117. [CrossRef]

16. Satsangi, A.; Sinha, K. Dynamics of Love and Happiness: A Mathematical Analysis. Mod. Educ. Comput. Sci. 2012, 5, 31-37. [CrossRef] 